\title{
The role of tumour-derived iNOS in tumour progression and angiogenesis
}

\author{
V Kostourou', ${ }^{1,2}$, JE Cartwright', AP Johnstone', JKR Boult ${ }^{3}$, ER Cullis', GStJ Whitley' and SP Robinson*,1,3 \\ 'Division of Basic Medical Sciences, St George's University of London, Cranmer Terrace, London SWI 7 ORE, UK; ${ }^{2}$ Institute of Immunology, BSRC \\ 'Alexander Fleming', 34 Fleming Street, Athens 16672, Greece; ${ }^{3}$ Cancer Research UK and EPSRC Cancer Imaging Centre, The Institute of Cancer \\ Research and Royal Marsden NHS Trust, Cotswold Road, Sutton, Surrey SM2 5NG, UK
}

\begin{abstract}
BACKGROUND: Progressive tumour growth is dependent on the development of a functional tumour vasculature and highly regulated by growth factors and cytokines. Nitric oxide (NO) is a free radical, produced both by tumour and host cells, and functions as a signalling molecule downstream of several angiogenic factors. Both pro- and antitumourigenic properties have been attributed to $\mathrm{NO}$. METHODS: The expression of the inducible isoform of NO synthase (iNOS) was knocked down in the C6 glioma cell line using constitutive expression of antisense RNA, and the effect of tumour-derived $\mathrm{NO}$ on tumour progression and angiogenesis was investigated.

RESULTS: Tumours in which iNOS expression was decreased displayed significantly reduced growth rates compared with tumours derived from parental C6 cells. Quantitative non-invasive magnetic resonance imaging and fluorescence microscopy of tumour uptake of Hoechst 33342, and haematoxylin and eosin staining, revealed significantly impaired vascular development and function in antisense iNOS tumours compared with control in vivo, primarily associated with the more necrotic tumour core. Decreased iNOS expression had no effect on tumour VEGF expression.

CONCLUSION: Nitric oxide derived from tumour iNOS is an important modulator of tumour progression and angiogenesis in C6 gliomas and further supports the therapeutic strategy of inhibiting iNOS for the treatment of cancer.

British Journal of Cancer (20II) I 04, 83-90. doi:I0.1038/sj.bjc.6606034 www.bjcancer.com

Published online 7 December 2010
\end{abstract}

(c) 201 I Cancer Research UK

Keywords: iNOS; nitric oxide; angiogenesis

Progressive tumour growth and survival is dependent on angiogenesis, the development of a functional blood supply to provide nutrients and remove waste products. Without the concomitant growth of new blood vessels or cooption of existing capillary networks, tumours cannot expand beyond a minimal size or metastasise to distant sites (Folkman, 1995; Carmeliet and Jain, 2000). Angiogenesis is stimulated by the release of specific growth factors from tumour, endothelial, accessory (stromal) host cells and/or associated macrophages, and production of these factors is upregulated by conditions associated with the classical hallmarks of the tumour microenvironment (e.g., elevated interstitial fluid pressure, hypoxia), all of which are consistent with a compromised blood supply (Yancopoulos et al, 2000). Although extensively studied, the molecular mechanisms that regulate tumour blood vessel development and function remain elusive, and are a reason for the apparent paucity of potent antiangiogenic therapies.

A plethora of angiogenic stimuli induce the production of nitric oxide (NO), an important inter- and intracellular signalling molecule synthesised from arginine by NO synthases (NOS). Of the three isoforms of NOS, specifically inducible (iNOS), endothelial (eNOS) and neuronal, iNOS produces the greatest

*Correspondence: Dr SP Robinson; E-mail: Simon.Robinson@icr.ac.uk Revised 3 November 2010; accepted 10 November 2010; published online 7 December 2010 amounts of NO and is associated with a number of pathologies (Moncada et al, 1991). Although their precise role is still unclear, both iNOS and eNOS activities have been implicated in tumour progression and angiogenesis, and their effectiveness appears to be dependent on their activity and distribution, the concentration and duration of exposure to NO, and the intrinsic sensitivity of cells to NO (Fukumura et al, 2006). For example, transfection of K-1735 murine melanoma with iNOS decreased the rate of tumour growth by inducing apoptosis (Xie et al, 1995). In contrast, overexpression of iNOS in DLD-1 colon carcinoma cells results in more aggressive and better vascularised tumours compared with wild type (Jenkins et al, 1995; Cullis et al, 2006). In addition, delivery of iNOS through gene transfer has been shown to both radiosensitise tumours and have direct cytotoxicity in vivo (Worthington et al, 2004). The results obtained from clinical studies have been more equivocal, revealing positive correlations between iNOS expression and grade in a wide range of human cancers, including brain tumours (Cobbs et al, 1995; Ellie et al, 1995; Ambs et al, 1998). More importantly, increased expression of iNOS in both human breast cancer and melanoma has recently been shown to be associated with poor outcome/survival (Loibl et al, 2005; Ekmekcioglu et al, 2006).

The effect of altered NO levels on tumour growth and angiogenesis has also been exploited through pharmacological manipulation with either NO donors or NOS inhibitors. Treatment of mice bearing mammary and squamous carcinomas with 
$N^{\mathrm{G}}$-nitro-L-arginine methyl ester, a universal NOS inhibitor, as well as specific inhibition of iNOS by either $1400 \mathrm{~W}$ or L-nil, reduced subcutaneous tumour growth and vessel development (Thomsen et al, 1997; Jadeski and Lala, 1999; Sikora et al, 2010). Although these observations indicate a tumour-promoting role for NO, the effect of NOS inhibition could not be ascribed specifically to tumour-derived NO, as NOS inhibition can affect other aspects of host physiology. These systemic effects were highlighted during studies in which low concentrations of NO donors inhibited angiogenesis and tumour growth, whereas higher doses of NO donors caused a reduced response because of interference with host physiology (Pipili-Synetos et al, 1995). A single dose of the NOS inhibitor $N^{\mathrm{G}}$-nitro-L-arginine (L-NNA) was shown to induce an acute and sustained reduction in human tumour blood volume, providing clinical evidence that inhibition of NOS has tumour antivascular effects $(\mathrm{Ng}$ et al, 2007). The importance of host-derived NO for tumour growth has also been shown genetically in studies using iNOS knockout mice, wherein tumour growth and vascularisation were decreased (Konopka et al, 2001; Wang et al, 2001). However, tumour cells are a major source of NO production that can affect angiogenesis and modulate tumour progression. Therefore, careful examination of the role of tumourderived NO is important in understanding tumour physiology and in the design of effective therapeutic interventions.

In this study we have investigated the role of tumour cellderived iNOS on growth and angiogenesis in a model of glioma, which clinically represents one of the most vascularised human cancers (Wesseling et al, 1997). The expression of iNOS in C6 glioma cells was reduced using an endogenous antisense approach, and the growth potential of these antisense-iNOS cells was examined in vivo. Furthermore, the functional blood supply of tumours derived from these manipulated cell lines was investigated in vivo using non-invasive magnetic resonance imaging (MRI), and complemented with fluorescence microscopy.

\section{MATERIALS AND METHODS}

\section{Cell culture and transfection}

The rat glioma C6 cell line (European Collection of Cell Cultures, Salisbury, UK) was maintained in Nutrient Ham's F-10 (Sigma, Dorset, UK) culture medium containing $2 \mathrm{~mm}$ L-glutamine, $100 \mathrm{U} \mathrm{ml}^{-1}$ penicillin, $0.1 \mathrm{mg} \mathrm{ml}^{-1}$ streptomycin and $10 \%(\mathrm{v} / \mathrm{v})$ fetal calf serum. The antisense iNOS stable-transfected cell lines (subsequently termed AS lines) were produced by transfection with the pciNOS500 plasmid using the poly L-ornithine method (Kostourou et al, 2002) and selected by culture in hygromycin $\left(500 \mu \mathrm{g} \mathrm{ml}^{-1}\right)$. For the generation of the pciNOS500 plasmid, the fragment of murine iNOS (5707-6247 bp), previously shown to be an effective antisense target (Cartwright et al, 2000), was extracted from the original clone in pSG5 vector using BamHI restriction enzyme and subcloned into the BamHI site in pcDNA $3.1(+) /$ hygro vector (Invitrogen, Paisley, UK).

\section{Western blot analysis}

Cell extracts were generated from stably transfected antisense cell lines (AS7, AS9 and AS12) and parental C6 cells with cytokine stimulation $\left(10 \mathrm{ng} \mathrm{ml}^{-1}\right.$ TNF- $\alpha, 100 \mathrm{U} \mathrm{ml}^{-1}$ IFN- $\gamma, 5 \mu \mathrm{g} \mathrm{ml}^{-1}$ LPS for $24 \mathrm{~h}$ ), and from tumour homogenates of AS7 and C6 tumours (Kostourou et al, 2002). Protein concentration was measured by the Bradford method according to the manufacturer's instructions (Sigma, Poole, Dorset, UK). An equal amount of protein was analysed by SDS-PAGE and the iNOS protein was detected using a polyclonal anti-mouse iNOS antibody (M-19, Santa Cruz, Heidelberg, Germany). Equal protein loading was verified on tumour homogenate blots using a monoclonal anti- $\beta$-actin antibody (AC-15, Abcam, Cambridge, UK).

\section{Nitrite production}

C6, AS7 and AS12 cells were stimulated with $10 \mathrm{ng} \mathrm{ml}^{-1}$ of TNF- $\alpha$, $100 \mathrm{U} \mathrm{ml}^{-1}$ of IFN- $\gamma$ and $5 \mu \mathrm{g} \mathrm{ml}^{-1}$ of LPS for up to $72 \mathrm{~h}$ and the nitrite production was determined using the Greiss reaction as previously described (Kostourou et al, 2002).

\section{In vitro growth}

The growth of C6 and AS7 cells under normal culture conditions or after cytokine stimulation $\left(5 \mu \mathrm{g} \mathrm{ml}^{-1}\right.$ LPS, $100 \mathrm{U} \mathrm{ml}^{-1}$ IFN- $\gamma$ and $10 \mathrm{ng} \mathrm{ml}^{-1}$ TNF- $\alpha$ ) was determined using a dye-binding assay, in which the concentration of the eluted dye is linearly correlated to the cell number (Winterbourne, 1993). AS7 and C6 cells were seeded at a density of 1000 cells per well in 24 -well plates. Fresh medium alone or with addition of cytokines was added every 2 days. Cell number was determined in duplicate wells at daily intervals for a period of 6 days. The cells were fixed in $300 \mu \mathrm{l}$ fixation solution $(10 \%(\mathrm{v} / \mathrm{v})$ formalin in $5 \%(\mathrm{w} / \mathrm{v})$ polyvinylpyrrolidone) for $5 \mathrm{~min}$. The wells were then washed three times with water and air-dried. The cells were stained with $600 \mu \mathrm{l}$ of filtered $0.04 \%(\mathrm{w} / \mathrm{v})$ Coomassie Blue R250 (Sigma) in 25\% $(\mathrm{v} / \mathrm{v})$ ethanol/12\% (v/v) acetic acid for $1 \mathrm{~h}$, washed three times with $600 \mu \mathrm{l}$ of $10 \%(\mathrm{v} / \mathrm{v})$ ethanol/5\% (v/v) acetic acid and allowed to dry. Cell growth was quantified by eluting the stain in $600 \mu \mathrm{l}$ filtered solution of $1 \mathrm{M}$ potassium acetate in $70 \%$ ethanol for $1 \mathrm{~h}$ and measuring absorbance at $620 \mathrm{~nm}$ using a Titertek Multiscan microtitre plate reader (Titertek, McLean, VA, USA).

\section{Animals and tumours}

All procedures were performed in accordance with the local ethical review panel, the UK Home Office Scientific Procedures Act 1986 and the UKCCCR guidelines (Workman et al, 2010). Female (7-8 weeks old) MF1/nu mice were injected subcutaneously in the flanks with AS7, AS12 or C6 cells in $0.1 \mathrm{ml}$ PBS. Tumour growth was measured at daily intervals after briefly anaesthetising the mice with fluothane in $2 \% \mathrm{~N}_{2} \mathrm{O}, 5 \% \mathrm{O}_{2}$. The dimensions of the tumour under the skin were measured using calipers and tumour volume was calculated using the following formula: tumour volume $=\pi / 6$. (length $\times$ width $\times$ depth $)$.

\section{Magnetic resonance imaging}

Fractional tumour blood volume was evaluated in vivo using susceptibility contrast MRI (Robinson et al, 2003). Intravascular contrast agents such as ultrasmall superparamagnetic iron oxide (USPIO) particles create magnetic susceptibility variations inducing an increase in the MRI transverse relaxation rate $R_{2}{ }^{*}\left(\mathrm{~s}^{-1}\right)$ of water in the surrounding tissue. Changes in tissue $R_{2}^{*}$ caused by USPIO particles are dependent on blood volume; hence, an estimate can be made by measuring the absolute changes in $R_{2}{ }^{*}$ following administration of USPIO particles. As USPIO particles probe for blood vessels that are functional at the time of injection, and not necrotic areas or vessels with static blood flow, a USPIO-induced measurement of $\Delta R_{2}{ }^{*}$ can provide a valuable non-invasive imaging biomarker associated with tumour angiogenesis (Kostourou et al, 2003; Robinson et al, 2008). A multigradient echo (MGRE) MRI sequence was used to quantify $R_{2}{ }^{*}$ of size-matched $\left(\sim 0.8 \mathrm{~cm}^{3}\right)$ AS7 and C6 tumours before and after the intravenous administration of $2.5 \mathrm{mg} \mathrm{Fe} \mathrm{kg}^{-1}$ of the USPIO contrast agent feruglose (GE Healthcare, Oslo, Norway) through a lateral tail vein. Apparent $R_{2}{ }^{*}$ maps were calculated on a voxel-byvoxel basis from the MGRE image data sets, and the average apparent $R_{2}{ }^{*}$ relaxation rates were calculated for each tumour for a 
region of interest encompassing the whole tumour image but excluding any surrounding skin and muscle. Having determined the $\Delta R_{2}{ }^{*}$ values $\left(R_{2}{ }^{*}\right.$ post-USPIO $-R_{2}{ }^{*}$ pre-USPIO), estimates of the fractional tumour blood volume $(\xi$, \%) were then derived as previously described (Robinson et al, 2003, 2008).

\section{Immunohistochemistry and fluorescence microscopy}

Mice bearing size-matched AS7 and C6 tumours were injected intravenously with $15 \mathrm{mg} \mathrm{kg}^{-1}$ of the perfusion marker Hoechst 33342 (Sigma) $1 \mathrm{~min}$ before excision of the tumour (Kostourou et al, 2003; Cullis et al, 2006). Three acetone-fixed cryosections $(8-10 \mu \mathrm{m})$ of each C6 and AS7 tumours were then visualised for Hoechst 33342 uptake by fluorescence microscopy using appropriate filters ( $355 \mathrm{~nm}$ excitation, $465 \mathrm{~nm}$ emission). To assess vessel density, additional frozen tumour sections were first rehydrated with $\mathrm{PBS}$, and then incubated with $2 \% \mathrm{BSA} / 5 \%$ goat serum in PBS for 30 min at room temperature. After washing with PBS, sections were incubated with rat anti-mouse PECAM monoclonal antibody (1:500 dilution, BD Pharmingen, Basingstoke, UK) for $1 \mathrm{~h}$ at room temperature, and then washed extensively in PBS/0.1\% Tween-20. Biotinylated anti-rat immunoglobulins $(1: 100$, Vector Laboratories, Burlingame, CA, USA) were then applied onto the sections and incubated for $1 \mathrm{~h}$ at room temperature. Following extensive washing in $\mathrm{PBS} / 0.1 \%$ Tween-20, sections were incubated with fluorescein streptavidin $(1: 100)$ in the dark for $30 \mathrm{~min}$, washed with $\mathrm{PBS} / 0.1 \%$ Tween-20 and mounted using Vectashield mounting medium (Vector Laboratories). Endothelial structures were subsequently visualised by fluorescence microscopy at $450-490 \mathrm{~nm}$. Whole tumour sections were scanned using a computer-controlled motorised scanning stage (Marzhauser, Wetzlar-Steindorf, Germany) driven by Stage-Pro (Media Cybernetics, Wokingham, UK) on an IX70 fluorescence microscope (Olympus Optical, London, UK). Digital images from both AS7 and C6 tumour sections were acquired using the same exposure time and composite images were synthesised. The digital images were analysed using analySIS software (Soft Imaging System, Munster, Germany). Fluorescent particles were detected above a constant threshold for all the composite images, and the area of the tumour section with fluorescein and Hoechst 33342 fluorescence was determined and expressed as a percentage of the whole tumour section. Additional formalin-fixed tumour sections were cut and stained with haematoxylin and eosin to assess tissue viability of AS7, AS12 and C6 tumours.

\section{Production and detection of VEGF}

Culture medium was collected from confluent six-well plates containing C6 and AS7 cells under normal culture conditions or after cytokine stimulation, and analysed for $\mathrm{VEGF}_{165}$ expression using a murine VEGF ELISA kit (R\&D Systems, Abingdon, UK). In addition, tumours were excised, weighed, cut into small pieces and maintained in culture medium for 4 days, following which the secretion of $\mathrm{VEGF}_{165}$ by the tumour explants into the culture medium was also determined by ELISA (Kostourou et al, 2002).

\section{RESULTS}

\section{Inhibition of iNOS expression in C6 glioma cells}

A number of hygromycin-resistant C6 cell lines were isolated following transfection with plasmid pcDNA 3.1 expressing a 500 base fragment of murine iNOS CDNA in an antisense orientation. The efficacy of this fragment to inhibit the expression of iNOS in these lines was determined by western blot analysis. Under basal conditions, the expression of iNOS by $\mathrm{C} 6$ cells was undetectable. On stimulation with TNF $\alpha$, IFN $\gamma$ and LPS for $24 \mathrm{~h}$, iNOS expression was increased (Figure 1A). In cells expressing antisense iNOS, there was variable but significant inhibition of iNOS expression. The most significant reduction in iNOS expression was exhibited by clones AS7 and AS12, and these lines were chosen for further investigations. The decrease in iNOS protein expression was corroborated by the reduced NO production by AS7 and AS12 cells, as determined by measuring the accumulation of nitrite following stimulation with TNF $\alpha$, IFN $\gamma$ and LPS for $24 \mathrm{~h}$. The AS7 and AS12 clones displayed significant inhibition of NO production $24 \mathrm{~h}$ after cytokine stimulation (76 and 63\%, respectively), compared with parental C6 cells, and this level of inhibition of iNOS activity remained similar at the later time point of $48 \mathrm{~h}$ (Figure 1B). The reduction in iNOS expression did not alter the in vitro growth properties of $\mathrm{C} 6$ cells. The basal- or
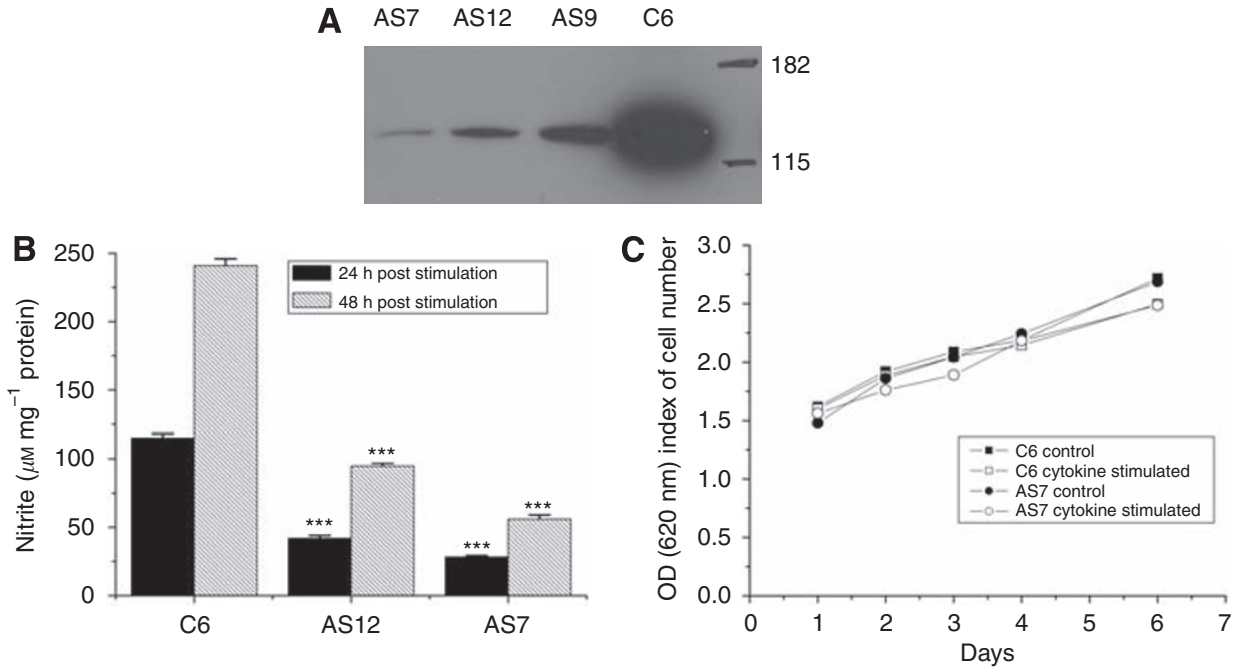

Figure I Characterisation of antisense iNOS cell lines in vitro. (A) Cytokine-induced $\left(10 \mathrm{ng} \mathrm{ml^{-1 }} \mathrm{TNF}-\alpha,\left|00 \mathrm{Uml^{-1 }}\right| \mathrm{FN}-\gamma, 5 \mu \mathrm{gml} l^{-1} \mathrm{LPS}\right.$ for $\left.24 \mathrm{~h}\right)$ iNOS expression from parental C6 and antisense iNOS clones AS7, AS9 and ASI2 determined by western blot. (B) Nitrite production in parental C6 and antisense iNOS clones AS7 and ASI2 determined 24 and $48 \mathrm{~h}$ after cytokine stimulation. Results are mean \pm I s.e.m. of triplicate of three separate experiments, ${ }^{*} * * * 0.001$, Student's $t$-test. $(\mathbf{C})$ In vitro growth rate of parental C6 and AS7 cells under normal culture conditions or after cytokine stimulation ( $\left.10 \mathrm{ng} \mathrm{ml}\right|^{-1}$ TNF- $\alpha, 100 \cup \mathrm{ml}^{-1}$ IFN- $\gamma$ and $\left.5 \mu \mathrm{g} \mathrm{ml}\right|^{-1}$ LPS). Results are mean \pm I s.e.m. of triplicate of three separate experiments. Note that decreased iNOS expression does not affect in vitro tumour cell growth and survival. 
cytokine-stimulated survival of AS7 cells was no different from that of parental C6 cells (Figure 1C).

\section{Effect of inhibiting iNOS expression on tumour growth in vivo}

In contrast to their growth in vitro, when AS7 or AS12 cells were inoculated into the flanks of nude mice, the tumour growth rate in vivo was significantly slower (AS7 doubling time of $\sim 5$ days) than that of C6 tumours (doubling time of $\sim 4$ days, Figure $2 \mathrm{~A}$ ). Tumours derived from AS12 cells exhibited a growth rate similar to that of AS7 tumours. AS7 tumours became palpable and measurable 13 days post inoculation of cells compared with C6 tumours, which could be measured 10 days post inoculation. After 20 days of growth, the mean tumour size of AS7 tumours was half that of C6 tumours. Inhibition of iNOS expression in AS7 tumours was confirmed by western blot analysis of tumour homogenates (Figure 2B).

\section{Effect of inhibiting iNOS expression on tumour vascular development}

Susceptibility contrast-enhanced MRI using the USPIO contrast agent feruglose was used to interrogate any differences in magnitude and distribution of fractional blood volume between size-matched C6 and AS7 tumours. Calculated $\Delta R_{2}{ }^{*}$ maps of C6 and AS7 tumours are shown in Figure 3A. Visual inspection of the tumour $\Delta R_{2}{ }^{*}$ maps consistently revealed that feruglose uptake was mainly restricted to the tumour periphery of AS7 tumours,
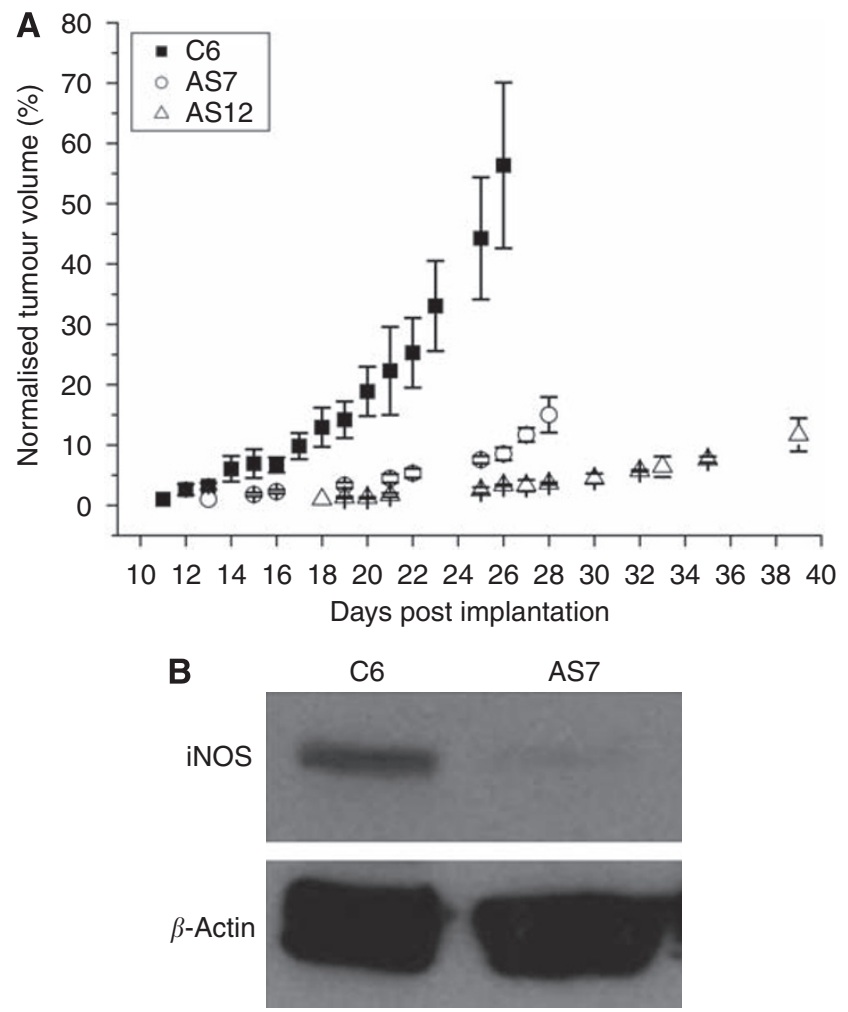

Figure 2 Effect of antisense iNOS on tumour growth in vivo. (A) Normalised growth rates of tumours derived from parental C6 $(n=6)$, AS7 $\left(2 \times 10^{6}, n=5\right)$ or $\operatorname{ASI} 2\left(1 \times 10^{6}, n=5\right)$ cells, grown subcutaneously in the flanks of female nude mice. Data points are mean \pm I s.e.m. Note the significantly slower growth rate of AS7 and ASI2 tumours. (B) Western blot of AS7 and C6 tumour homogenates, showing reduced expression of iNOS in the AS7 tumours. compared with the more heterogeneous $\Delta R_{2}^{*}$ maps of C6 tumours. Administration of feruglose significantly increased $R_{2}^{*}$ of the C6 tumours only (Figure 3B). The mean fractional tumour blood volume $(\xi)$ derived from these data was $1.4 \pm 0.1 \%$ and $0.9 \pm 0.2 \%$ for C6 and AS7 tumours, respectively.

Tumour perfusion was also assessed by quantifying the uptake of the fluorescent perfusion marker Hoechst 33342. This is a nuclear dye that, on injection, stains endothelial cells and cells immediately adjacent to tumour blood vessels. The time from injection to euthanisation was limited to $1 \mathrm{~min}$ to prevent excessive diffusion of the dye beyond the cells lining perfused blood vessels within the tumour. Thus, Hoechst 33342 uptake reports only on functionally perfused vessels, and also provides validation of the MRI data. Composite images of Hoechst 33342 uptake showed that, as with MRI data, AS7 tumours had fewer perfused areas compared with C6 tumours, and that these regions were restricted mainly to the tumour periphery (Figure 4A). The perfused vessels were quantified using image analysis techniques and the mean perfused area of AS7 tumours was significantly lower compared with that of C6 tumours (Figure 4B). In comparison, the pan-endothelial marker PECAM was more homogeneously and extensively distributed across both C6 and AS7 tumours, with no significant difference in vessel density between the two tumour types (Figure $4 \mathrm{~A}$ and $\mathrm{C}$ ). Composite images of whole haematoxylin and eosin-stained sections of C6, AS7 and AS12 tumours are shown in Figure 4C. Essentially, the darker stain is indicative of more viable tissue. Histological examination of the sections showed that AS7 and AS12 tumours exhibited a high degree of tissue heterogeneity, central necrosis and reduction of viable tissue, consistent with insufficient perfusion, compared with the more homogeneous and viable parental C6 gliomas.

\section{Decreased AS7 tumour perfusion is not mediated by decreased VEGF expression}

Nitric oxide has also been shown to both stimulate and inhibit VEGF expression in a cell-dependent manner and is a potent modulator of vascular development and tumour progression (Chin et al, 1997; Tsurumi et al, 1997; Liu et al, 1998; Yancopoulos et al, 2000). In vitro studies of AS7 and C6 cells showed that both cell lines produced similar levels of $\mathrm{VEGF}_{165}$. Induction of iNOS with cytokines for $24 \mathrm{~h}$ resulted in a significant 1.5 -fold upregulation of VEGF $_{165}$ in both AS7 and C6 cell lines (Figure 5A). In addition, the concentration of $\mathrm{VEGF}_{165}$ in the medium of tumour explants exhibited no significant differences between AS7 and C6 tumours, as determined by ELISA (Figure 5B).

\section{DISCUSSION}

The effect of NO, and in particular tumour cell-derived NO, on tumour growth and angiogenesis is still unclear. Numerous preclinical studies have implicated NO in both tumour growth and angiogenesis in vivo with controversial conclusions (Jenkins et al, 1995; Thomsen et al, 1997; Ambs et al, 1998; Jadeski and Lala, 1999; Camp et al, 2006; Cullis et al, 2006; Sikora et al, 2010). The majority of these studies used pharmacological manipulation of NO with either NO donors or inhibitors. There are, however, several disadvantages with this approach, including the lack of NOS isoform selectivity of existing inhibitors, and their systemic effects on host physiology. In addition, NO donors can rapidly generate high levels of NO, together with other cytotoxic molecules such as cyanide, reactive nitrogen intermediates, peroxynitrite and superoxide, making it impossible to dissect the role of NO from the cytotoxicity caused by other reactive species (Borutaite et al, 2000). In vivo, cells are more likely to experience lower concentrations of NO over prolonged time periods. 

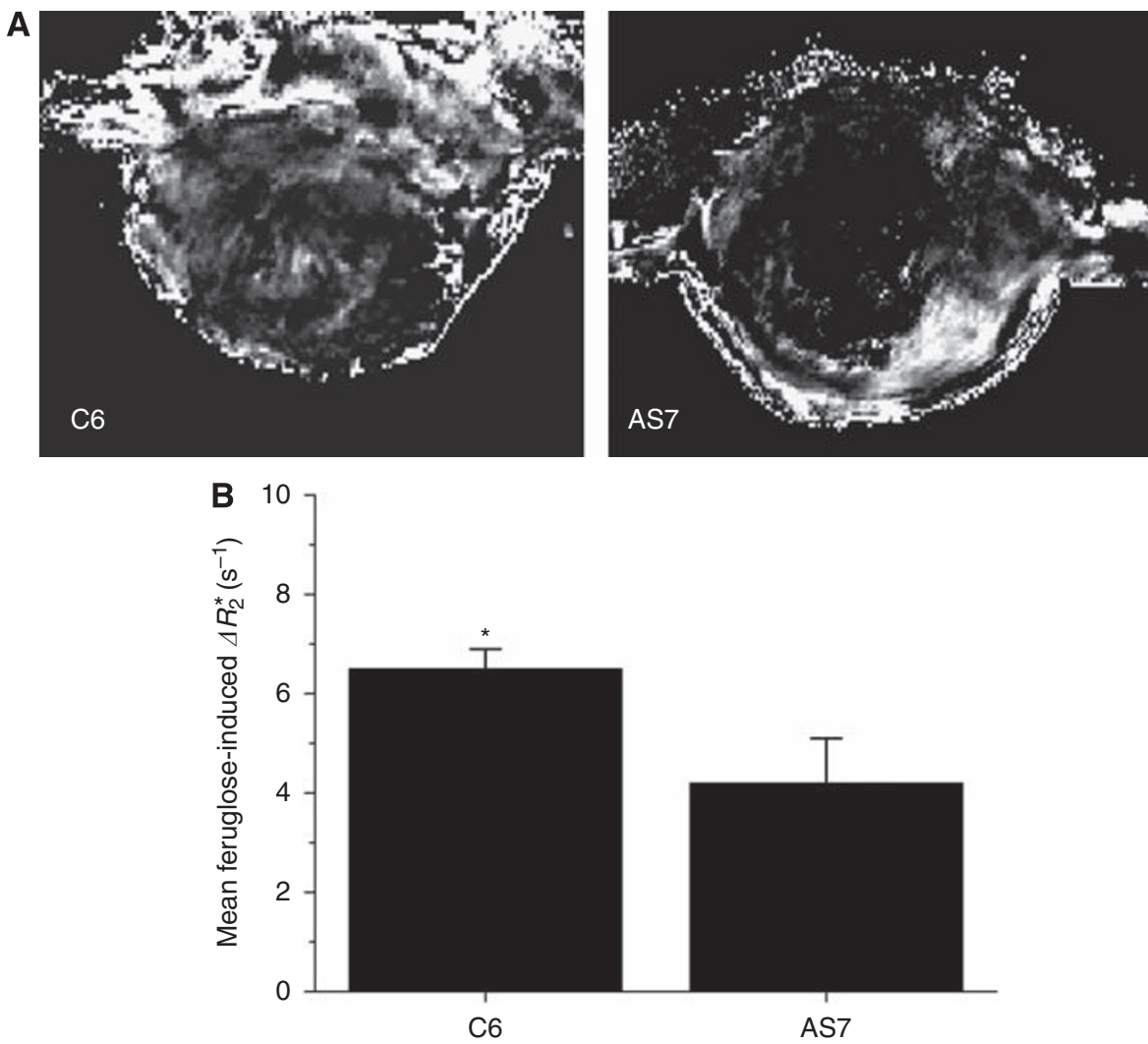

Figure 3 Effect of antisense iNOS on tumour blood volume assessed by MRI. (A) Calculated $\Delta R_{2} *$ maps of C6 and AS7 tumours. Note the dark core within the core of the map of the AS7 tumour, indicating an absence of feruglose uptake within these regions. (B) Summary of feruglose-induced $\Delta R_{2} *$ of parental C6 $(n=6)$ and AS7 $(n=7)$ tumours. Results are mean \pm I s.e.m. $* P<0.05$, Student's t-test.

In this study, an alternative approach was taken that aimed to overcome some of these shortcomings. Instead of overexpressing the iNOS isoform, which could result in non-physiological, extremely high levels of NO, the role of iNOS on tumour growth and angiogenesis was studied by more subtly decreasing endogenous iNOS expression using antisense technology. Rat C6 glioma cells, which express iNOS, were used, as tumours derived from them represent a well-established model of human glioblastoma (Simmons and Murphy, 1992; Barth, 1998). Furthermore, positive correlations of malignancy with iNOS expression have been shown in human brain tumours (Cobbs et al, 1995; Ellie et al, 1995), which typically present as highly vascularised tumours in the clinic (Wesseling et al, 1997). Although the growth rate of these cells in vitro was unaltered, tumours derived from the iNOS-antisensetransfected C6 cell lines displayed significantly reduced growth in vivo compared with tumours derived from wild-type C6 cells. Compared with control, cytokine-stimulated AS7 and AS12 clones exhibited a clear reduction in iNOS expression and nitrite production in vitro, and reduced iNOS expression was found in AS7 tumours.

Together, these data emphasise the importance of tumour cell-derived iNOS in the progression of C6 gliomas. The absence of a substantial difference in iNOS expression in vivo presumably reflects contributions of iNOS from accessory cells, especially macrophages, within solid tumours. Propagation and interrogation of tumours from these clones in iNOS knockout mice should provide an even more unambiguous assessment of the contribution of tumour cell-derived iNOS. Using a similar antisense approach, Yamaguchi et al (2002) reported that decreased iNOS expression resulted in reduced glioma formation in an orthotopic rat C6 striatal implantation model. However, the mechanism for the failure of tumour growth was not clarified. It was speculated that decreased expression of iNOS in tumour cells may render them more sensitive to the host immune response. Here we provide evidence for an alternative mechanism by which tumourderived NO affects tumour growth. Determination of fractional tumour blood volume by non-invasive susceptibility contrast MRI, and histologically qualified with fluorescence microscopy of Hoechst 334342 uptake, revealed that decreased tumour growth is a result of a dysfunctional vascular network that did not support effective tumour perfusion, particularly within the tumour core.

To accommodate sustained tumour growth, the vasculature has to undergo constant remodelling. As a part of this process and as a result of the elevated interstitial fluid pressure (IFP) associated with tumours, and because of local imbalances of angiogenic factors and or intermittent blood flow, some vessels within the tumour may collapse and cease to function. Although these vessels will stain positive for endothelium and contribute to the vessel density measurements, they will not necessarily contribute to tumour growth (Eberhard et al, 2000). We therefore used susceptibility contrast MRI in vivo and fluorescence microscopy of Hoechst 33342 uptake to assess the degree and distribution of any functional differences in the perfusion of vessels derived from the two cell types in vivo, and showed that inhibition of iNOS resulted in reduced tumour perfusion primarily restricted to the tumour periphery. Nitric oxide is a potent mediator of tumour vascular tone (Fukumura et al, 2006). Sustained functional tumour perfusion, assessed by Hoechst 33342 uptake, within the core of DLD-1 colon carcinomas derived from cells constitutively overexpressing iNOS, has been reported, and it was hypothesised that the increased concentration of NO may abrogate any IFP-induced vascular collapse (Cullis et al, 2006). Similarly, inhibition of iNOS 


\section{A}
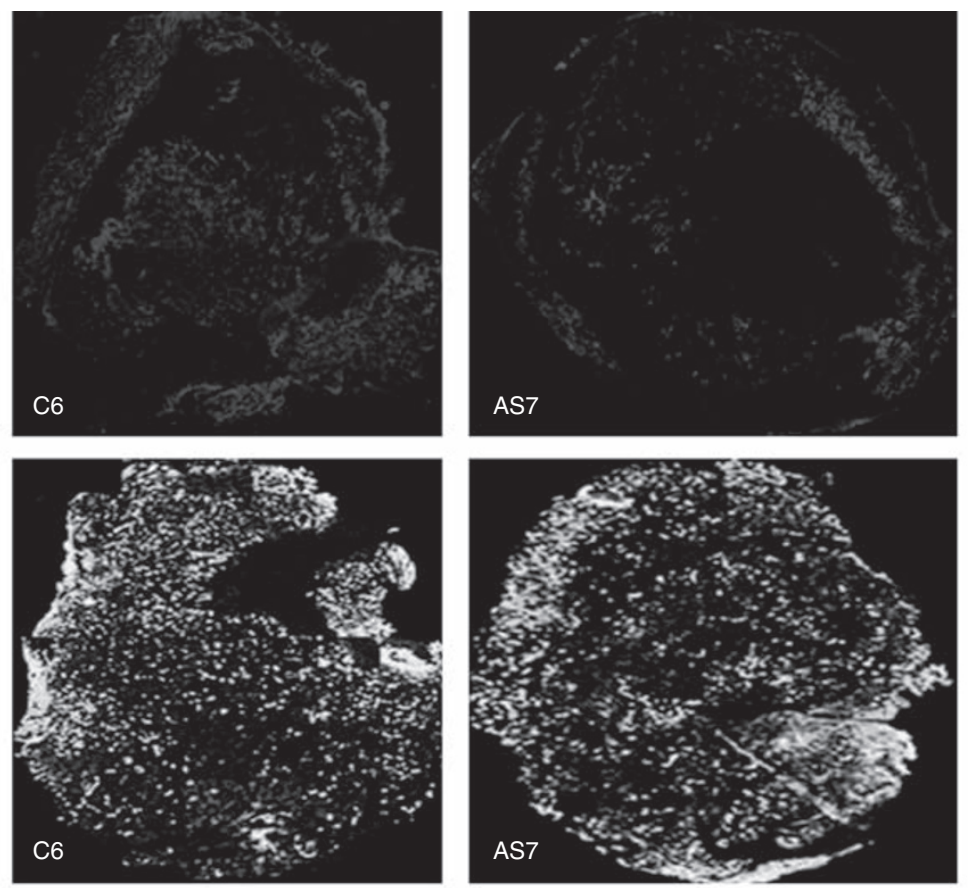

\section{B}

\section{C}

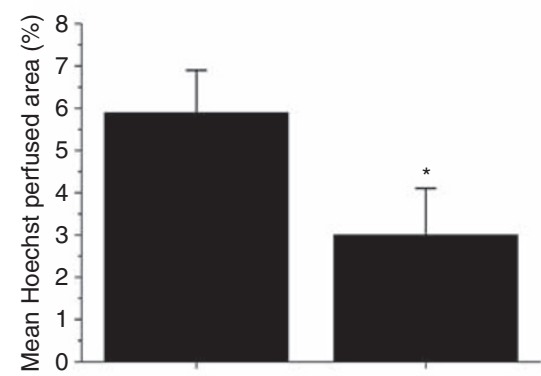

C6

AS7

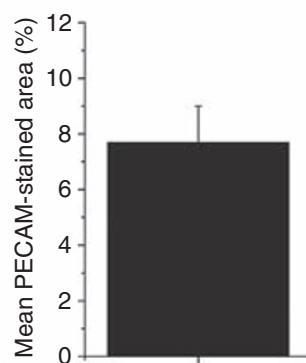

C6

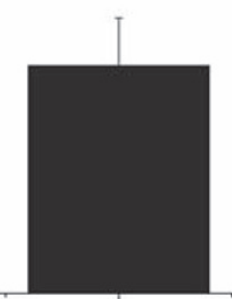

AS7

D
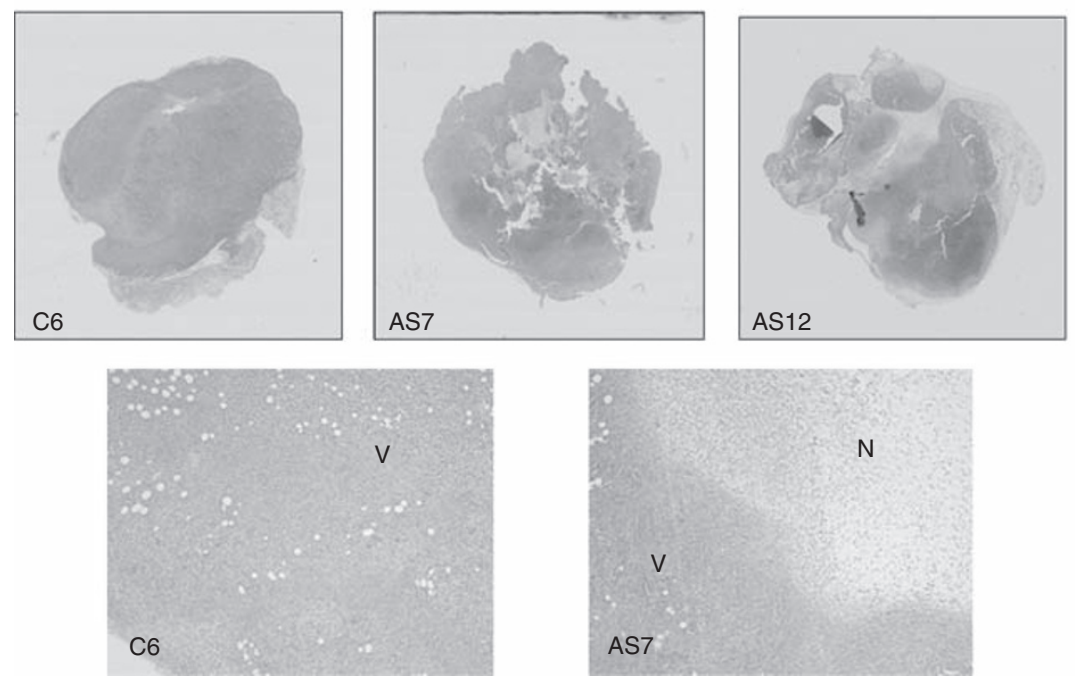

Figure 4 Assessment of tumour perfusion by fluorescence microscopy. (A) Composite fluorescence images of Hoechst 33342 uptake, and PECAM staining, in whole C6 and AS7 tumour sections. Note that Hoechst 33342 uptake is restricted to the periphery of the AS7 tumour. (B) Quantitation of Hoechst 33342 uptake (mean Hoechst perfused area, \%) obtained from three sections each of C6 $(n=5)$ and AS7 ( $n=4)$ tumours. (C) Quantitation of vascular density (mean PECAM stained area, \%) obtained from sections of C6 $(n=6)$ and AS7 $(n=4)$ tumours. Results are mean \pm I s.e.m., * $P<0.05$, Student's t-test. (D) Composite images of whole haematoxylin and eosin-stained sections of tumours derived from C6, AS7 or ASI 2 cells, and localised images ( $\times 40$ magnification) acquired from within the same sections. Parental C6 tumours exhibited homogeneous, viable (V) tissue, whereas the AS7 and ASI2 tumours presented with increased central necrosis $(N)$ and a reduction of viable tissue. 

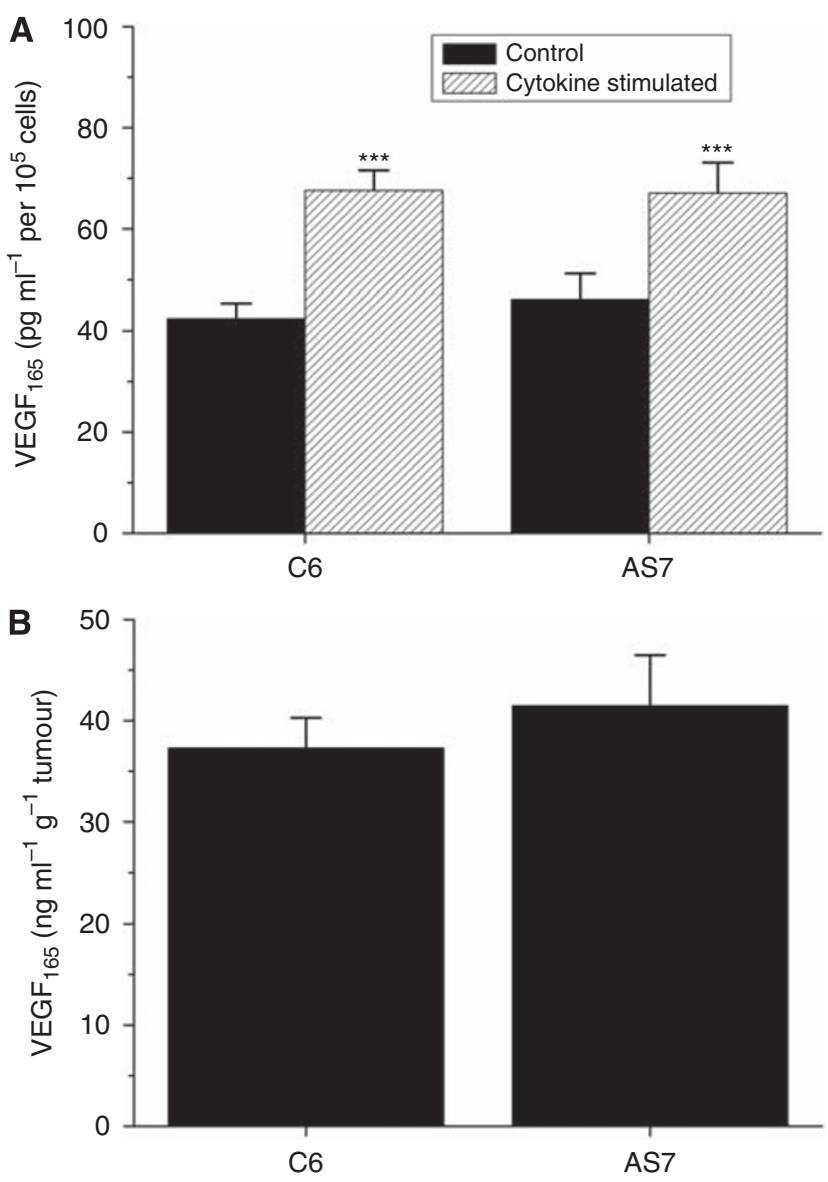

Figure 5 Effect of antisense iNOS on VEGF expression in vitro and ex vivo. (A) VEGF 165 production by parental C6 and AS7 cells under normal culture conditions or $24 \mathrm{~h}$ after cytokine stimulation $\left(\left.10 \mathrm{ng} \mathrm{m}\right|^{-1}\right.$ TNF- $\alpha, 100 \cup \mathrm{ml}^{-1} \mathrm{IFN}-\gamma$ and $5 \mu \mathrm{g} \mathrm{ml}^{-1}$ LPS). Results are mean \pm I s.e.m. of duplicate of three separate experiments. ${ }^{*} * * P<0.00$ I, Student's $t$-test. (B) The VEGF 165 production by C6 and AS7 tumour explants. Results are mean \pm I s.e.m. of triplicate of two separate experiments.

may facilitate IFP-induced vascular collapse, resulting in the absence of functional tumour perfusion within the AS7 tumours reported herein.

\section{REFERENCES}

Ambs S, Bennett WP, Merriam WG, Ogunfusika MO, Oser SM, Harrington AM, Shields PG, Felley-Bosco E, Hussain SP, Harris CC (1999) Relationship between p53 mutations and inducible nitric oxide synthase expression in human colorectal cancer. J Natl Cancer Inst 91: 86-88

Ambs S, Merriam WG, Bennett WP, Felley-Bosco E, Ogunfusika MO, Oser SM, Klein S, Shields PG, Billiar TR, Harris CC (1998) Frequent nitric oxide synthase-2 expression in human colon adenomas: implication for tumor angiogenesis and colon cancer progression. Cancer Res 58: $334-341$

Barth RF (1998) Rat brain tumor models in experimental neuro-oncology: the 9L, C6, T9, F98, RG2 (D74), RT-2 and CNS-1 gliomas. J Neuro Oncol 36: $91-102$

Benjamin LE, Keshet E (1997) Conditional switching of vascular endothelial growth factor (VEGF) expression in tumors: induction of endothelial cell shedding and regression of hemangioblastoma-like vessels by VEGF withdrawal. Proc Natl Acad Sci USA 94: 8761-8766

Borutaite V, Morkuniene R, Brown GC (2000) Nitric oxide donors, nitrosothiols and mitochondrial respiration inhibitors induce caspase activation by different mechanisms. FEBS Lett 467: 155-159
Several factors have been implicated in tumour development, one of the most prominent being VEGF, which induces sprouting angiogenesis, increases blood vessel permeability and maintains tumour vessel integrity (Yancopoulos et al, 2000). The expression of VEGF has been shown to be a survival factor for blood vessels in C6 gliomas (Benjamin and Keshet, 1997). Nitric oxide can induce VEGF expression and mediate the angiogenic effects of VEGF (Ambs et al, 1999). We therefore hypothesised that the reduced growth and vessel perfusion of AS7 tumours would be associated with decreased VEGF expression. However, our in vitro and ex vivo analyses of VEGF expression and production in tumour cells and explants revealed no significant differences between AS7 and C6 gliomas, coupled with no difference in vessel density as revealed by PECAM immunohistochemistry. Endothelial NOS has been shown to have a predominant role in VEGF-induced angiogenesis (Fukumura et al, 2001). This, coupled with the data herein, suggests that NO produced from iNOS activity is important in the maintenance of tumour blood vessel tone and function, and further highlights the apparent differing roles of the NOS isotypes, and their tissue/cell type of origin, on tumour angiogenesis in vivo.

In conclusion, we have shown (i) by using an antisense approach that NO derived from tumour cell expression of iNOS is a key modulator of tumour growth and angiogenesis, and (ii) the ability of susceptibility contrast MRI to non-invasively assess the effects of tumour-derived iNOS on vascular development and function in C6 gliomas in vivo. Inhibition of NOS following treatment with L-NNA has been shown to have antivascular activity in human tumours ( $\mathrm{Ng}$ et al, 2007). Together, these data further support the concept of inhibiting iNOS as a therapeutic strategy for the treatment of cancer.

\section{ACKNOWLEDGEMENTS}

This work was supported by a St George's Hospital Medical School $\mathrm{PhD}$ studentship awarded to VK, Cancer Research UK grant C12/A1209, the British Heart Foundation, the Biotechnology and Biological Sciences Research Council, grant S20430, and The Royal Society. We acknowledge the support received by The Institute of Cancer Research CRUK and EPSRC Cancer Imaging Centre in association with the MRC and Department of Health (England; grant C1060/A10334), and NHS funding to the NIHR Biomedical Research Centre. SPR is the recipient of a Royal Society University Research Fellowship. The authors thank Glyn Fisher and his staff for care of the animals.
Camp ER, Yang A, Liu W, Fan F, Somcio R, Hicklin DJ, Ellis LM (2006) Roles of nitric oxide synthase inhibition and vascular endothelial growth factor receptor-2 inhibition on vascular morphology and function in an in vivo model of pancreatic cancer. Clin Cancer Res 12: $2628-2633$

Carmeliet P, Jain RK (2000) Angiogenesis in cancer and other diseases. Nature 407: 249-257

Cartwright JE, Johnstone AP, Whitley GS (2000) Endogenously produced nitric oxide inhibits endothelial cell growth as demonstrated using novel antisense cell lines. Br J Pharmacol 131: 131-137

Chin K, Kurashima Y, Ogura T, Tajiri H, Yoshida S, Esumi H (1997) Induction of vascular endothelial growth factor by nitric oxide in human glioblastoma and hepatocellular carcinoma cells. Oncogene 15: 437-442

Cobbs CS, Brenman JE, Aldape KD, Bredt DS, Israel MA (1995) Expression of nitric oxide synthase in human central nervous system tumors. Cancer Res 55: $727-730$

Cullis ER, Kalber TL, Ashton SE, Cartwright JE, Griffiths JR, Ryan AJ, Robinson SP (2006) Tumour overexpression of inducible nitric oxide synthase (iNOS) increases angiogenesis and may modulate the 
anti-tumour effects of the vascular disrupting agent ZD6126. Microvasc Res 71: 76-84

Eberhard A, Kahlert S, Goede V, Hemmerlein B, Plate KH, Augustin HG (2000) Heterogeneity of angiogenesis and blood vessel maturation in human tumors: implications for antiangiogenic tumor therapies. Cancer Res 60: $1388-1393$

Ekmekcioglu S, Ellerhorst JA, Prieto VG, Johnson MM, Broemeling LD, Grimm EA (2006) Tumor iNOS predicts poor survival for stage III melanoma patients. Int J Cancer 119: $861-866$

Ellie E, Loiseau H, Lafond F, Arsaut J, Demotes-Mainard J (1995) Differential expression of inducible nitric oxide synthase mRNA in human brain tumours. Neuroreport 7: 294-296

Folkman J (1995) Angiogenesis in cancer, vascular, rheumatoid and other disease. Nat Med 1: 27-30

Fukumura D, Gohongi T, Kadambi A, Izumi Y, Ang J, Yun CO, Buerk DG, Huang PL, Jain RK (2001) Predominant role of endothelial nitric oxide synthase in vascular endothelial growth factor-induced angiogenesis and vascular permeability. Proc Natl Acad Sci USA 98: 2604-2609

Fukumura D, Kashiwagi S, Jain RK (2006) The role of nitric oxide in tumour progression. Nat Rev Cancer 6: $521-534$

Jadeski LC, Lala PK (1999) Nitric oxide synthase inhibition by N(G)-nitroL-arginine methyl ester inhibits tumor-induced angiogenesis in mammary tumors. Am J Pathol 155: 1381-1390

Jenkins DC, Charles IG, Thomsen LL, Moss DW, Holmes LS, Baylis SA, Rhodes P, Westmore K, Emson PC, Moncada S (1995) Roles of nitric oxide in tumor growth. Proc Natl Acad Sci USA 92: 4392-4396

Konopka TE, Barker JE, Bamford TL, Guida E, Anderson RL, Stewart AG (2001) Nitric oxide synthase II gene disruption: implications for tumor growth and vascular endothelial growth factor production. Cancer Res 61: $3182-3187$

Kostourou V, Robinson SP, Cartwright JE, Whitley GS (2002) Dimethylarginine dimethylaminohydrolase I enhances tumour growth and angiogenesis. Br J Cancer 87: 673-680

Kostourou V, Robinson SP, Whitley GS, Griffiths JR (2003) Effects of overexpression of dimethylarginine dimethylaminohydrolase on tumor angiogenesis assessed by susceptibility magnetic resonance imaging. Cancer Res 63: 4960 - 4966

Liu Y, Christou H, Morita T, Laughner E, Semenza GL, Kourembanas S (1998) Carbon monoxide and nitric oxide suppress the hypoxic induction of vascular endothelial growth factor gene via the $5^{\prime}$ enhancer. J Biol Chem 273: $15257-15262$

Loibl S, Buck A, Strank C, von Minckwitz G, Roller M, Sinn HP, Schini-Kerth V, Solbach C, Strebhardt K, Kaufmann M (2005) The role of early expression of inducible nitric oxide synthase in human breast cancer. Eur J Cancer 41: 265-271

Moncada S, Palmer RM, Higgs EA (1991) Nitric oxide: physiology, pathophysiology, and pharmacology. Pharm Rev 43: 109-142

Ng Q-S, Goh V, Milner J, Stratford MR, Folkes LK, Tozer GM, Saunders MI, Hoskin PJ (2007) Effect of nitric-oxide synthesis on tumour blood volume and vascular activity: a phase I study. Lancet Oncol 8: 111-118

Pipili-Synetos E, Papageorgiou A, Sakkoula E, Sotiropoulou G, Fotsis T, Karakiulakis G, Maragoudakis ME (1995) Inhibition of angiogenesis, tumour growth and metastasis by the NO-releasing vasodilators, isosorbide mononitrate and dinitrate. Br J Pharmacol 116: 1829-1834

Robinson SP, Ludwig C, Paulsson J, Östman A (2008) The effects of tumor-derived platelet-derived growth factor on vascular morphology and function in vivo revealed by susceptibility MRI. Int J Cancer 122: $1548-1556$

Robinson SP, Rijken PF, Howe FA, McSheehy PM, van der Sanden BP, Heerschap A, Stubbs M, van der Kogel AJ, Griffiths JR (2003) Tumor vascular architecture and function evaluated by non-invasive susceptibility MRI methods and immunohistochemistry. J Magn Reson Imaging 17: $445-454$

Sikora AG, Gelbard A, Davies MA, Sano D, Ekmekcioglu S, Kwon J, Hailemichael Y, Jayaraman P, Myers JN, Grimm EA, Overwijk WW (2010) Targeted inhibition of inducible nitric oxide synthase inhibits growth of human melanoma in vivo and synergizes with chemotherapy. Clin Cancer Res 16: $1834-1844$

Simmons ML, Murphy S (1992) Induction of nitric oxide synthase in glial cells. J Neurochem 59: 897-905

Thomsen LL, Scott JM, Topley P, Knowles RG, Keerie AJ, Frend AJ (1997) Selective inhibition of inducible nitric oxide synthase inhibits tumor growth in vivo: studies with $1400 \mathrm{~W}$, a novel inhibitor. Cancer Res 57: $3300-3304$

Tsurumi Y, Murohara T, Krasinski K, Chen D, Witzenbichler B, Kearney M, Couffinhal T, Isner JM (1997) Reciprocal relation between VEGF and NO in the regulation of endothelial integrity. Nat Med 3: $879-886$

Wang B, Xiong Q, Shi Q, Tan D, Le X, Xie K (2001) Genetic disruption of host nitric oxide synthase II gene impairs melanoma-induced angiogenesis and suppresses pleural effusion. Int J Cancer 91: 607-611

Wesseling P, Ruiter DJ, Burger PC (1997) Angiogenesis in brain tumors; pathobiological and clinical aspects. J Neuro Oncol 32: 253-265

Winterbourne DJ (1993) Chemical assays for proteins. Meth Mol Biol 19: $197-202$

Workman P, Aboagye EO, Balkwill F, Balmain A, Bruder G, Chaplin DJ, Double JA, Everitt J, Farningham DA, Glennie MJ, Kelland LR, Robinson V, Stratford IJ, Tozer GM, Watson S, Wedge SR, Eccles SA, Navaratnam V, Ryder S (2010) Guidelines for the welfare and use of animals in cancer research. Br J Cancer 102: 1555-1577

Worthington J, McCarthy HO, Barrett E, Adams C, Robson T, Hirst DG (2004) Use of the radiation-inducible WAF1 promoter to drive iNOS gene therapy as a novel anti-cancer treatment. J Gene Med 6: 673-680

Xie K, Huang S, Dong Z, Juang S, Gutman M, Xie Q, Nathan C, Fidler I (1995) Transfection with the inducible nitric oxide synthase gene suppresses tumorigenicity and abrogates metastasis by K-1735 murine melanoma cells. J Exp Med 181: 1333-1343

Yamaguchi S, Bell HS, Shinoda J, Holmes MC, Wharton SB, Whittle IR (2002) Glioma tumourgenicity is decreased by iNOS knockout: experimental studies using the C6 striatal implantation glioma model. Br J Neurosurg 16: $567-572$

Yancopoulos GD, Davis S, Gale NW, Rudge JS, Wiegand SJ, Holash J (2000) Vascular-specific growth factors and blood vessel formation. Nature 407: $242-248$ 